\title{
PRISIONEROS DE SU PROPIO OFICIO. LOS CACIQUES DEL LAGO TITICACA EN LAS CÁRCELES PÚBLICAS DEL SUR ANDINO (SIGLOS XVI-XVII)
}

\author{
PRISONERS OF THEIR OWN OFFICE. THE CACIQUES OF THE TITICACA \\ LAKE IN SOUTH ANDEAN PUBLIC JAILS (16 $16^{T H}-17^{\text {TH }}$ CENTURIES)
}

Ariel J. Morrone*

\begin{abstract}
Este trabajo reconstruye los derroteros de un elenco de caciques "de menor porte" de los pueblos de reducción de los corregimientos adyacentes al lago Titicaca entre fines del siglo XVI y mediados del siglo XVII, específicamente de quienes pasaron largas y recurrentes estadías en las cárceles públicas por no haber cumplido con las cargas coloniales (el tributo monetizado y mita potosina). Entre los pueblos, las ciudades y las cárceles, sus denodados esfuerzos permiten vislumbrar sus dificultades y las contradicciones del duro oficio de la intermediación social y política. Buscamos interpelar estas experiencias históricas en el marco de la cultura jurídica de la época, como así también insertarlas en los marcos historiográficos de los liderazgos étnicos en el mundo andino colonial.

Palabras claves: Liderazgo étnico, cacicazgo, cárcel pública, mediación política.
\end{abstract}

This paper reconstructs the paths of a cast of lesser caciques (native lords) of the pueblos de reducción (villages) of the corregimientos (rural jurisdictions) adjacent to Lake Titicaca between the end of the $16^{\text {th }}$ and mid-1 $7^{\text {th }}$ centuries, specifically of those who spent long and recurrent stays in public jails for not having fulfilled the colonial charges (the monetized tribute and the Potosi mita). Among the pueblos, cities and jails, their strenuous efforts allow us to glimpse at their difficulties and the contradictions of the intricate craft of social and political intermediation. We seek to question these historical experiences in the framework of the legal culture of that time, and insert them in the historiographical frameworks about ethnic leaderships in the colonial Andean world.

Key word: Ethnic leadership, chiefdom, public jail, political mediation.

\section{Introducción}

Unas hileras de luz se filtraban entre las tablas gruesas de la puerta del calabozo. Poco a poco cruzaban la pared trasera del cuarto, se amarillaron y desvanecieron. Los mismos hilos de luz entre las tablas se volvían grises, se apagaban. Sebastián dormitaba de rato en rato; soñaba con comida. No había probado bocado después de salir de Oyune al amanecer. Después había pasado el día encerrado en Takesi; un día llegando a La Paz; el interrogatorio en la noche; otro día después del interrogatorio. Ya eran tres días, y nada más que agua (Spedding 1997:143).

\section{Consideraciones historiográficas iniciales}

Entre las transformaciones protagonizadas por las poblaciones indígenas del mundo andino a partir de la implantación de un sistema de dominación colonial durante el gobierno del virrey don Francisco de Toledo (1569-1581), la refuncionalización de las figuras de liderazgo étnico y sus mecanismos de reproducción y transformación ocuparon un lugar central en la agenda de investigación historiográfica de la década de 1970 (Wachtel 1976 [1971]; Spalding 1974; Rivera Cusicanqui 1978). En efecto, solo algunos kuraka o mallku prehispánicos se transformaron en "caciques principales y gobernadores" de los recientemente fundados pueblos de reducción, responsables de garantizar el flujo ascendente de tributo, el reclutamiento de la mano de obra para el abastecimiento de la explotación minera de Potosí y la evangelización de sus sujetos, organizados en ayllus en torno al parentesco, la reproducción de la vida material y el control de recursos tales como la tierra, el agua, el ganado y la mano de obra.

Los estudios etnohistóricos abordaron las diversas modalidades de intermediación desplegadas por estas autoridades tanto para conservar sus

* Consejo Nacional de Investigaciones Científicas y Técnicas (CONICET), Programa de Historia de América Latina (PROHAL), Instituto de Historia Argentina y Americana “Dr. Emilio Ravignani”, Facultad de Filosofía y Letras, Universidad de Buenos Aires. Dirección postal: 25 de Mayo 221, segundo piso. Ciudad Autónoma de Buenos Aires (1002), Argentina. Correo electrónico: arielmorri@yahoo.com.ar 
privilegios políticos, materiales y simbólicos como para, en algunos casos, templar el peso de las cargas coloniales (Stern 1986 [1982]). Desde entonces, el liderazgo étnico como problema de investigación se articuló en torno de un esquema analítico tripartito, en donde el cacique ocupó una posición de "bisagra entre dos mundos". Esa posición estuvo sustentada, en efecto, por una "doble legitimidad": la heredada de la tradición prehispánica y la otorgada por la nueva situación colonial (Saignes 1987b). Las relaciones entabladas entre el cacique y el segmento dominante de la sociedad revelaron los canales de acción/reacción frente a las exigencias del gobierno colonial y sus agentes, y a la dinámica de los mercados surandinos en plena diversificación. Apelar a los estrados judiciales y detectar fisuras e intersticios en el sistema de dominación permitió mitigar los efectos disruptivos de la nueva correlación de fuerzas. Esta perspectiva rescata su protagonismo y su historicidad en una situación estructuralmente desigual (Saignes 1985; Harris, Larson y Tandeter 1987; Moreno y Salomon 1991; Pease 1992).

Estudios regionales y de caso posteriores determinaron los alcances de estos procesos a diferentes escalas de la organización territorial (pueblo de reducción, corregimiento, audiencia). La ampliación del panorama historiográfico permitió generar consensos en el campo académico en torno a la ambigüedad y la variabilidad de las prácticas articuladas por algunos caciques en el contexto colonial (Stern 1987), en tanto sus prácticas mercantiles, políticas y culturales posibilitaron la cohesión social de sus ayllus. En el sur andino, tanto la cuenca del lago Titicaca como el macizo central de Charcas fueron escenarios privilegiados para el despliegue de trabajos multidisciplinarios que reconstruyeron la historia prehispánica y temprano-colonial de las unidades sociopolíticas nativas para enmarcar así el rol mediador de sus líderes. A partir de las conquistas incaica e hispánica, estos avances dieron detallada cuenta de las transformaciones acaecidas en el acceso a recursos, los patrones de asentamiento y movilidad y los criterios materiales y simbólicos de legitimación de las autoridades étnicas (Choque Canqui 2003; del Río 2005; Platt et al. 2006; Medinacelli 2010; Presta 2013). En la actualidad, la historiografía revisita el período toledano y del propio proceso reduccional, atendiendo al rol que de los caciques en la imposición/negociación de la fundación de los pueblos, en la confección de las nuevas matrículas tributarias y en sus avatares hasta mediados del siglo XVII (Diez Hurtado 2006; Wernke 2007; Mumford 2012; Zuloaga 2012; Zagalsky 2013; Graubart 2016; Oliveto 2017; del Río 2018). Del mismo modo, nuevos aportes indagan los saberes, técnicas y prácticas escriturarias asociadas al grado de "literalidad" (literacy) de los caciques andinos, algunos de estos llegaron a presentar sus causas en las cortes de Lima, Sevilla o Madrid (Glave 2006; Burns 2011; Charles 2010; Dueñas 2010; Yannakakis 2013; de la Puente Luna 2014, 2015, 2018; Jurado 2014; Ramos 2016; Quispe-Agnoli 2016; Castro Flores 2019).

Tras medio siglo de producción historiográfica, las investigaciones concluyen en que la implantación de la economía mercantil y del ordenamiento jurídico-político hispánico habilitó espacios para el enriquecimiento personal de los caciques, "escaladores sociales" que transitaron senderos individuales hacia la incorporación de pautas culturales del segmento dominante. Mediante complejos protocolos de persuasión e intermediación, estos caciques basaron su éxito económico en estrategias de reposicionamiento que integraban la participación en los mercados y el sostenimiento de sus respectivas economías étnicas. La administración de los bienes colectivos (tierras y agua, ganado, alimentos y cosechas, dinero de las cajas de comunidad) y las ganancias mercantiles posibilitaron que estos caciques adquirieran propiedades inmuebles (estancias rurales, solares y casas en las ciudades), solventaran peticiones judiciales, cumplieran con los tributos, conmutaran mitayos y abonaran a la construcción y "aderezo" de iglesias en sus pueblos. En paralelo, su enriquecimiento permitió la progresiva patrimonialización de los recursos colectivos, la puesta en marcha de negocios en el "espacio el trajín", el reclutamiento de contingentes propios de mano de obra y el pago de salarios a artesanos y otros especialistas. Asimismo, en virtud de su inserción en el esquema del gobierno colonial, los caciques articularon redes clientelares, eventualmente redistribuyeron entre sus ayllus las riquezas acumuladas, consolidaron su legitimidad, adquirieron renombre en el escenario político local y forjaron linajes asociados a un patrimonio heredable y un apellido transmisible ${ }^{1}$.

Pero no todos los caciques pudieron resolver "exitosamente" el desafío de la intermediación. Muchos se vieron entrampados en los entresijos de su posición política, "fracasando" en satisfacer 
las exigencias coloniales y la reproducción de sus ayllus. ¿Qué ocurría, pues, con estos caciques menos afamados, verdaderos "caciques del fracaso", cuando las instancias judiciales no eran suficientes, se cerraban o fallaban en su contra? Ya empobrecidos tras la enajenación de los bienes propios y colectivos, se endeudaron con particulares para enterar las excesivas tasas, cuyos cronogramas no lograban cumplir. La dejación del oficio, la cárcel pública, la huida e incluso el suicidio conformaban el único abanico de opciones disponibles, quedando sus ayllus desprotegidos y despoblados. En efecto, estos caciques no solo no traspasaron sus apellidos a la generación siguiente ni instituyeron linajes, sino que algunos incluso procuraron desvincular a sus descendientes del oficio. Su menor dotación de recursos económicos y relacionales se tradujo en una marcada "invisibilidad documental", lo que a su vez dificultó su tratamiento historiográfico: los caciques pobres han sido, casi siempre, los principales ausentes en las reconstrucciones históricas de los mapas políticos del sur andino (Saignes 1987a:129-130, 1987b:146). Desprovistos de legitimidad, riquezas y redes, estos caciques se vieron compelidos a abroquelarse y escudarse detrás de otros más prominentes para paliar, cuanto menos en parte, su desventajosa situación (Morrone 2011, 2016).

En este trabajo nos proponemos sistematizar la información disponible de las circunstancias que llevaron a varios caciques de los corregimientos cercanos al lago Titicaca a las cárceles públicas de los pueblos de reducción y de las ciudades de La Paz y Potosí entre fines del siglo XVI y la primera mitad del siglo XVII (ver Figura 1). Para ello, exploramos nuestras notas de archivo y confeccionamos una matriz preliminar que nos permitió trazar patrones comunes y extraer conclusiones del conjunto de la muestra. Previo al análisis, presentaremos las características generales, funciones y significados de las cárceles públicas en el sistema jurídico-político colonial. Luego, enfocamos dos situaciones en las riberas sur y norte del lago para incorporar sus experiencias al marco general, para finalmente cerrar con un conjunto de reflexiones a modo de balance.

\section{Apuntes sobre la cárcel pública: entrar, habitar, salir}

En la cultura jurídica y en la práctica política de la época, la cárcel pública era un lugar de permanencia transitoria para quienes contravenían algún aspecto del corpus normativo, hasta tanto tuviera lugar la resolución judicial del caso. Más que un castigo en sí mismo, la permanencia en la cárcel pública sustraía al justiciable en cuestión de su inserción en las redes habituales de sociabilidad, buscando "poner en policía" a quienes se apartaran del "orden de la república", como un castigo ejemplar visible ante el resto de los habitantes, en sintonía con la concepción corporativa, organicista y paternalista de las sociedades iberoamericanas de la época (Hespanha 1993:98-105; Agüero 2005)².

Como en otras ciudades indianas, la cárcel pública de La Paz funcionó inicialmente en el edificio del cabildo o en alguna casa anexa. A diez años de fundada la ciudad, en noviembre de 1558 los vecinos encomenderos a cargo de su gobierno decidieron emprender las obras para la construcción de la casa capitular en un solar frente a la plaza principal, donde asimismo viviría el corregidor y funcionarían la cárcel y la fundición. Para ello, solicitaron al virrey don Andrés Hurtado de Mendoza, marqués de Cañete, la suma de 2000 pesos de oro y contemplaron emplear mano de obra nativa proveniente de varios repartimientos realengos comarcanos. Para agosto de 1559 los vecinos precisaban más fondos para finalizar las obras, los que se propusieron recaudar por su propia cuenta. Dos años después, en marzo de 1561, denunciaron que solo habían recibido la mitad del dinero prometido por el virrey, por lo que encomendaron a un regidor la organización de las obras restantes. Finalmente, la cárcel ya se encontraba en funciones en julio de 1561 (Feyles 1965:942, 976-977, 994-996, 1047, 1112, 1140-1441). Las escrituras públicas de inicios del siglo XVII, por su parte, ubican la cárcel en la manzana emplazada frente al convento agustino; más adelante, entre 1625 y 1660, fue trasladada a la calle que va desta plaça al convento de la Merced ${ }^{3}$.

Poco sabemos de la dinámica interna de la cárcel pública de La Paz. No contamos con documentación complementaria (solicitudes de presos, libros de visitas) para reconstruir algún aspecto de la vida cotidiana en la cárcel ${ }^{4}$. Nuestro abordaje descansa, en efecto, en una selección de escrituras públicas y expedientes judiciales que registran la prisión de algunos caciques lacustres en la ciudad, pero también en sus respectivos pueblos de reducción y en Potosí.

Siguiendo las pautas hispanas de organización espacial, la fundación de los pueblos de reducción, con su planta ortogonal centrada en la plaza, también 


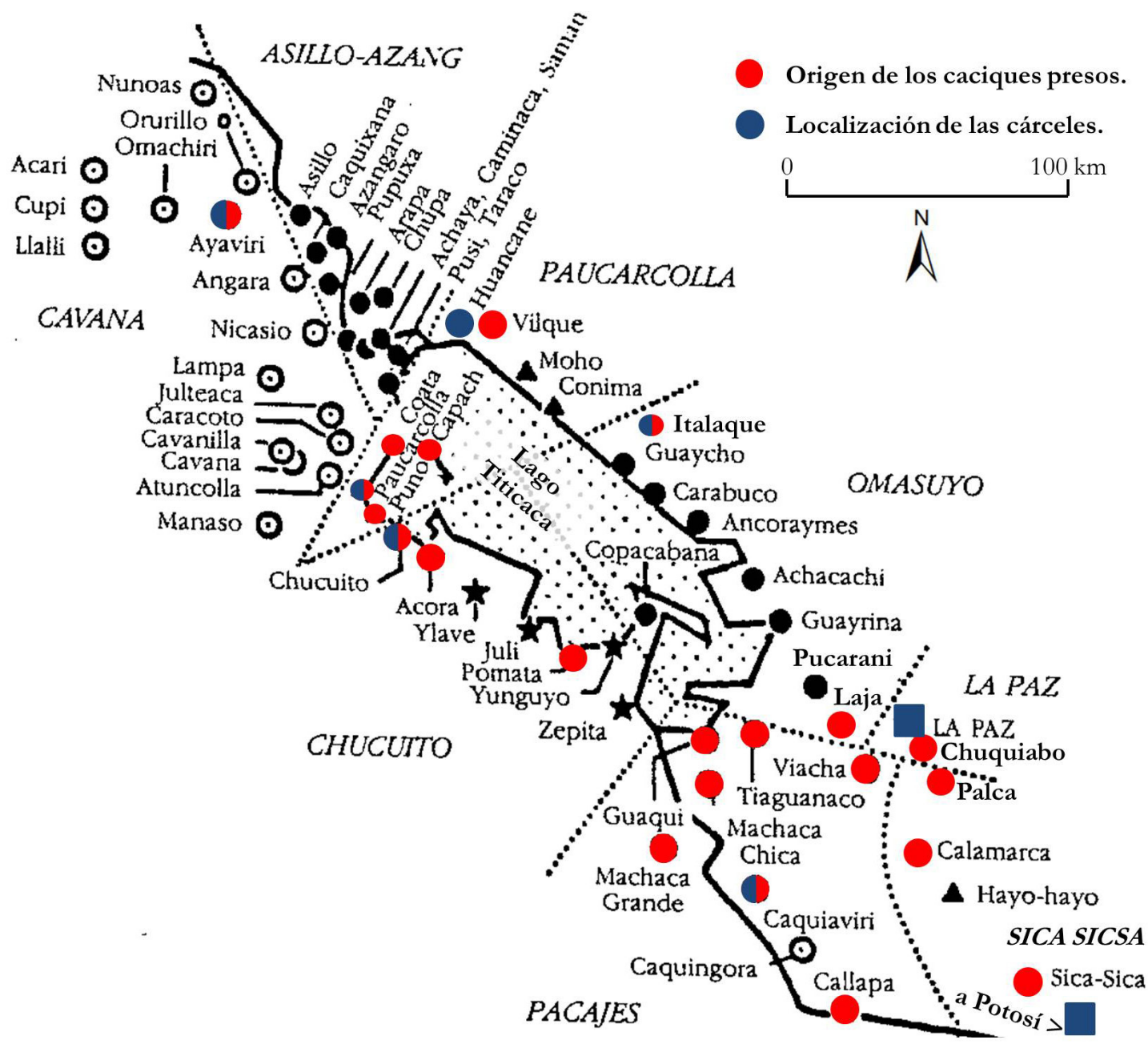

Figura 1. Registros de caciques presos en los corregimientos del lago Titicaca, La Paz y Potosí (1576-1650). Elaboración del autor a partir de Wachtel 2001:339.

contemplaba la construcción de una cárcel con las mismas características de sus pares citadinas. Juan de Matienzo así lo recomendaba e ilustraba en su arquetípico plano: en los dos solares que están detrás de la casa de el Corregidor, se ha de hacer la casa del tucuirico y la cárcel, adonde ha de haber dos cepos y cuatro pares de grillos y dos cadenas ${ }^{5}$.

Las ordenanzas toledanas establecían que el corregidor debía procurar que la construcción de los edificios para el gobierno del pueblo, entre ellos la cárcel, siguiera la traza establecida por los visitadores $^{6}$. En tanto rasgo del nuevo paisaje socialmente construido, y funcional a los objetivos del dominio colonial, la cárcel pública replicaba las jerarquías de la sociedad estamental donde estaba inserta, como una "caja de resonancia" de las contradicciones, desavenencias y conflictos atravesados por las autoridades étnicas cuando, ante el incumplimiento de sus funciones, eran tomados prisioneros por "desordenar las cuentas de la república".

Nuestra exploración documental arrojó 32 registros de caciques prisioneros de su propio oficio para el período 1576-1650: la mitad de ellos en cárcel pública La Paz, diez en las de sus respectivos pueblos de reducción y seis en la de Potosí. A partir de esta muestra, nos interrogamos acerca de las circunstancias de ingreso de esos caciques a las cárceles, las características del tratamiento al que se vieron sometidos y las condiciones en que lograron salir. 
En cuanto a las causas que llevaron a los caciques a prisión, en 21 casos se trató de deudas, en su mayoría con la Real Hacienda por rezagos de tributos, aunque también con sus curas doctrineros por el sínodo, con particulares beneficiarios de los remates de sus tributos o con acreedores por préstamos. Siete casos correspondieron a conflictos en torno a la mita potosina (entero de mitayos, abusos de mineros y funcionaros, abandono del oficio de capitán de mita); dos podrían rotularse genéricamente como "transgresiones" (desconocimiento de autoridad cacical, involucramiento en embargo del encomendero) mientras que en otros dos no constan motivos.

El retraso en el pago del tributo establecido en la tasa toledana (o en retasas posteriores) ponía en marcha un circuito administrativo en donde la autoridad competente (generalmente los oficiales de la Real Hacienda o los corregidores, en persona o por comisión) exigía a los caciques la entrega de los bienes y del dinero adeudado. Ante la imposibilidad de responder a estas obligaciones, se producía el embargo de los bienes personales del cacique para su remate en pública almoneda, con el objetivo de cancelar los "alcances" de la deuda en cuestión. Cuando aun así lo procedido del remate no alcanzaba a cubrir el "rezago", el paso siguiente consistía en el apresamiento del cacique y su reclusión en la cárcel pública (Stern 1986:167-168; Saignes 1987b:146-147). Otro mecanismo que llevaba a prisión a los caciques consistía en el reclamo de los bienes adeudados por parte del beneficiario del remate. En este sentido, el ingreso y permanencia en las cárceles remitía al concepto de "encierrogarantía" (Foucault 1996:38), con esto se buscaba poner al deudor bajo custodia hasta tanto saldara la deuda contraída.

Varios fueron los caciques lacustres apresados por deudas con el real erario. Los caciques de Chuquiabo (pueblo fundado frente al casco urbano paceño) estuvieron presos en la cárcel de la ciudad en 1608, 1612, 1613 y 1624. Sus pares de San Andrés y Santiago de Machaca (1606), Callapa (1610) y Pucarani (1615) tuvieron que responder a los reclamos que los beneficiaros de los remates de los bienes tributados, generalmente notables vecinos paceños o sus agentes. Finalmente, en 1630 los caciques de Achacachi y Julloma contrajeron préstamos con hispanocriollos y enajenaron propiedades inmuebles propias para saldar sus deudas y evitar así el encarcelamiento (Morrone 2016).
Del cruce de expedientes judiciales obtuvimos indicios del tratamiento dado a los caciques presos por motivos tocantes a la mita potosina. Así, en 1593 el juez comisionado por el corregidor de Potosí para el reclutamiento de mitayos del pueblo de Ayaviri (corregimiento de Cabana y Cabanilla) apresó a los caciques don Fernando Pay y don Diego Coaquira, quienes no habían enterado la cuota establecida, y los pusi en el sepo compresiones y tome la llave de la puerta de la carcel y los dexe çerrados ${ }^{7}$. En la misma línea, en 1618 don Diego Dávila de Herrera, corregidor de Pacajes, explicaba cómo por orden del licenciado don Gabriel Gómez de Sanabria, fiscal de la Audiencia de Charcas designado por el gobierno virreinal para el reclutamiento forzoso de mitayos para el recientemente descubierto yacimiento de Oruro, debió apresar a casi todos los caciques de su jurisdicción en la cárcel de Caquiaviri por negarse a cumplir con una obligación que entendían excesiva. Advertía el corregidor: de manera que si no es castigarlos corporalmente no queda otra $\cos a^{8}$. Por su parte, los cuatro caciques de Laja (corregimiento de Omasuyos) denunciaron ante el corregidor durante la revisita efectuada en 1625 que los jueces comisionados que llegaban de Potosí les an colgado y cuelgan de los cabellos en horca publica puestos en carceles grillos y demas prisiones ${ }^{9}$. Incluso un renombrado cacique surandino como don Gabriel Fernández Guarachi sufrió en carne propia los efectos lacerantes de los grillos y las cadenas en la cárcel de Potosí cuando, en 1646, amenazó con abandonar el estratégico oficio de capitán de mita. A pesar de su intento, la huida del capitán designado para el año siguiente, don Juan Chuqui Mamani, cacique de Caquiaviri, lo puso nuevamente a cargo del entero de la mita, por lo que en abril de 1647 estaría nuevamente preso, pues debía indemnizar a varios mineros por los mitayos faltantes de Guaqui y Tiwanaku ${ }^{10}$.

Esta evidencia de castigos corporales informa respecto del carácter apremiante de la situación de los caciques caídos en desgracia. Entre 1602 y 1604, el jesuita Alonso Messia presentó un memorial ante el virrey don Luis de Velasco por la situación general de la mita potosina. Messia recomendaba enfáticamente a los corregidores de la Villa poner presos a los caciques que abusaran de mitayos: sabiendo que lo hacen, castigarlos con treinta dias de cárcel á la primera vez, y con destierro á la segunda, de suerte que no se atreverán más á hacerlo (Torres de Mendoza 1866;VI:159). Tanto 
dentro como fuera de la cárcel, mitayos y caciques se encontraban bajo la vigilancia de las autoridades potosinas y bajo amenaza de ser castigados ante el menor "desacomodo" del rendimiento de la actividad minera.

¿Quiénes habitaban las cárceles citadinas? De regreso en La Paz, durante la primera mitad del siglo XVII hallamos en la cárcel a miembros de los estamentos inferiores de la sociedad paceña: dos esclavos, un yanacona preso por deudas, un tributario que asesinó a otro, un español que asesinó al cacique de la parroquia de San Sebastián, otro español por deudas al colegio jesuita, otros tres por robo de mulas ${ }^{11}$. Pero en la misma cárcel pública estuvieron recluidos tanto el contador Gregorio Pardo de Aguiar durante la auditoría de sus cuentas al frente de la Caja Real de La Paz en 1619 como el depositario general Pedro de Mena por deuda de remates en $1626^{12}$. Si bien con seguridad los presos de diferentes orígenes étnicos y calidades merecieron tratamientos diferenciados en función de sus respectivos estatus, entendemos que algún tipo de interacción debió haberse dado entre ellos (aunque de momento desconocemos sus pormenores).

Si la cárcel pública funcionó como "estación de paso" para los caciques, la salida estaba sujeta a la presencia de fiadores que pudieran saldar los montos establecidos para tal fin (Argouse 2015). Así, en 1593 los caciques de Ayaviri, presos por el entero de mitayos, lograron salir de la cárcel del pueblo gracias a la fianza pagada por un particular, mientras que en 1612 don Diego Topo Catari, cacique de Sica Sica, fue fiador de su par don Pedro Pacaxe, quien se hallaba en la cárcel de Potosí por adeudar más de 200 pesos al capitán de mita don Baltasar Cusi. Tanto en ese año como en 1613, el cacique de Chuquiabo don Andrés Chuqui Guanca y su segunda persona don Carlos Cari salieron de la cárcel de La Paz bajo la fianza pagada por Gaspar Hernández, oficial cerrajero. En 1630, el licenciado don Pedro de Pisa y Saavedra, cura de Viacha y miembro de la elite paceña, dejó asentado en su testamento que había dado a don Pedro Callisaya, cacique del pueblo, la suma de 60 pesos para sacarlo de la cárcel de la ciudad ${ }^{13}$. La presencia de fiadores que pudieran responder con sus bienes por los caciques presos constituye una ventana de acceso a las redes relacionales que estas autoridades podían articular (en nuestro caso, con un oficial cerrajero y con el cura doctrinero del pueblo), incluso en un contexto desfavorable como la prisión por deudas.
Otros caciques fueron liberados por las propias autoridades que los habían apresado, generalmente con el objetivo de completar las cargas fiscales adeudadas. Tal fue el caso de don Felipe Molle, cacique principal de Vilque (corregimiento de Paucarcolla), y don Alonso Molle, alcalde del mismo pueblo, quienes en mayo de 1600 fueron liberados de la cárcel del pueblo de Guancané por el corregidor ${ }^{14}$. Retomaremos esta modalidad de salida en el apartado siguiente, cuando analicemos la situación específica de los caciques de Paucarcolla a fines de la década de 1640 .

Finalmente, otra forma (trágica más que efectiva) de "liberarse" de la cárcel era el suicidio. El jesuita Messia recuperó en su informe el testimonio de un cacique, quien entre lágrimas le confesó en 1601 el nivel de extenuación al que había llegado tras agotar todas las opciones disponibles:

\section{Padre, yo estoy obligado á enterar treinta y un indios, y destos há seis meses que me faltan diez y seis, y cada semana los he enterado y pagado ciento veinte $\mathrm{y}$ seis pesos en alquilarlos, y para esto he vendido una mula que tenia, mis carneros y mis vestidos que tenia, y he buscado plata prestada, echando derrama entre mis indios; y no teniendo remedio para entregar los indios, la semana pasada empeñé una hija que tengo, á un español, porque me prestase sesenta y cuatro pesos que me faltaban, y la semana que viene, no sé qué hacerme, sino ahorcarme (Torres de Mendoza 1866;VI:159-160. Cf. Zagalsky 2014a: 388).}

Ingresar, permanecer, habitar y (de alguna u otra manera) salir de la cárcel fueron prácticas habituales para los caciques de bajo porte que no encontraron mecanismos de ascenso hacia posiciones de relevancia política a escala regional. Incluso para algunos grandes caciques surandinos, caer presos formaba parte de "los gajes del oficio", aunque claramente disponían de mayores respaldos para desembarazarse de tal incómoda vicisitud. En las páginas siguientes, enfocaremos dos situaciones, ancladas en la primera mitad del siglo XVII, que nos permitirán avanzar en la caracterización de estos liderazgos cuya mediación sociopolítica se vio truncada por su debilidad estructural. 


\section{Salir de prisión para "morir de pesar": el cacique de Guaqui (1618-1633)}

Tal como mencionamos en el apartado anterior, en 1618 el licenciado Gómez de Sanabria presionó al corregidor de Pacajes para que pusiera presos en la cárcel de Caquiaviri a aquellos caciques que se opusieran a la leva de mitayos. Entre los once caciques presos encontramos a don Baltasar Guamani, cacique de Guaqui hurinsaya, quien sería liberado a los pocos días gracias a la mediación de don Gabriel Cusi Quispe, cacique de Caquiaviri y gran líder político regional (Morrone 2013). Años después, en 1623, Guamani fue convocado a declarar en la causa incoada por los oficiales de la Real Hacienda contra su encomendero, el gobernador Francisco de Barrasa y Cárdenas, por el embargo de los tributos del repartimiento. El comisionado de la Real Hacienda quiso apresar al cacique y a don Sebastián Laura, su segunda persona ${ }^{15}$. Si bien en esa oportunidad don Baltasar Guamani adujo que de presente esta enfermo e yndispuesto y respeto del mal tiempo que haçe si se pusiese en camino correria gran riesgo su vida, en 1631 nuevamente estaría preso en la cárcel pública de La Paz por deudas de tributos y envargado mis bienes en particular cierta cantidad de vacas cargas de chuño y otras cosas que tenia para mi sustento ${ }^{16}$.

Las reiteradas amenazas motivaron al cacique de Guaqui a sumarse, en 1633, a las filas de don Gabriel Fernández Guarachi, cacique de Jesús de Machaca, en su enfrentamiento con don Antonio Mogollón de Rivera, corregidor de La Paz, por un conjunto de mitayos que este había ocultado para sus propios intereses ${ }^{17}$. Frente a este nuevo conflicto en torno al abastecimiento de mitayos, don Baltasar Guamani no dudó en abroquelarse junto con otros caciques del corregimiento de Pacajes detrás de una figura política de renombre como lo era el cacique de Jesús de Machaca, tal como quince años antes lo había hecho con el cacique de Caquiaviri.

¿A qué factores obedecía esta práctica recurrente? Durante las primeras décadas del siglo XVII, los habitantes de Guaqui y sus caciques atravesaron una situación endémica de despoblamiento. En primer lugar, la población tributaria venía cayendo desde la visita toledana: si en 1573 el visitador había registrado 1280 tributarios, promediando el siglo, la visita general ordenada en 1645 por el virrey don Pedro de Toledo y Leiva, marqués de Mancera, registró en Guaqui solo a 203 “indios naturales”, lo que representaba una caída del $84 \%$ respecto de los tiempos toledanos ${ }^{18}$. Para 1657 , los caciques de Guaqui cumplirían con menos del $15 \%$ de sus obligaciones tributarias totales ${ }^{19}$. Las limitaciones y tribulaciones que atravesaba el pueblo de Guaqui incluso habían motivado a que, en marzo de 1609, su encomendero considerara la posibilidad de hacer dejación de la encomienda ${ }^{20}$.

Como es esperable, verificamos las mismas dificultades a la hora de evaluar el entero de la mita: para 1617, los caciques de Guaqui solo pudieron enterar menos del 14\% de los mitayos exigidos (Saignes 1987a:52). Junto con Tiwanaku, Caquingora y Santiago de Machaca, Guaqui fue uno de los pueblos más acabados y caídos en lo concerniente a la provisión de su cuota mitaya para la leva de 1644, según informó dos años después el protector de naturales de Potosí al corregidor de la Villa en nombre de don Gabriel Fernández Guarachi, capitán general de la mita para ese año ${ }^{21}$.

Si bien la notoria "disipación" del pueblo respondía a la caída general de la población tributaria en el sur andino durante las últimas décadas del siglo XVI y las primeras del siglo XVII (Saignes 1987a), en el caso de Guaqui intervinieron dos factores específicos que agravaron la situación. Por un lado, los pueblos de la ribera sur del lago Titicaca (Zepita, Guaqui, Tiwanaku, Jesús y San Andrés de Machaca) sufrieron reiterados ataques y asaltos por parte de los yndios uros poblados en el asiento de Ochosuma ${ }^{22}$. La amenaza constante generada por estos ataques fue una de las razones de la deserción de los habitantes de estos pueblos (Wachtel 2001:362-367). Asimismo, las inundaciones ocurridas en las lagunas de Potosí el 15 de marzo de 1626 causaron estragos en los mitayos de Guaqui y Tiwanaku y sus familias, pues por muchas ymformaçiones consta que se ynundaron y ahogaron mas de mil familias y con ellas mas de 5000 personas de dichos pueblos ${ }^{23}$.

Ejercer el oficio de cacique en circunstancias como las descriptas fue por demás espinoso. Nuevamente, el protector de naturales de Potosí retrataba en 1646 el deplorable estado de situación:

para el buen entero se valen de sus haciendas, y muchos y casi todos reconociendo que se les siguen por obviar vejaciones y molestias tienen a buen partido el perderlas y quedar destruidos y aniquilados, como ha sucedido con don Baltasar Mamani, don Agustín 
Yucra Guanca, don Sebastian Marca, don Juan Cupiticona, que de pesar, viéndose destruidos y aniquilados, habiendo sido lo mejor y más aplaudido de sus pueblos, se han muerto $(\ldots)^{24}$.

La muerte de don Baltasar Guamani, acaecida entre 1633 y 1646, siguió los pasos de aquellos caciques que murieron de pesadumbre por aver gastado sus haçiendas en el entero de la dicha mita y quedar tan pobres y aniquilados que no tuvieron a que volver los dichos por los yndios faltos de otros pueblos que les haçen enterar ${ }^{25}$. Condicionado por debilidades internas y amenazas externas, perdidos sus bienes y abatido su liderazgo, el cacique de Guaqui penduló entre la cárcel pública de La Paz y el abroquelamiento estratégico bajo la influencia de dos grandes líderes regionales, para finalmente retirarse a morir en el silencio documental. Como veremos, no todos los caciques caídos en desgracia tuvieron a mano una figura de mayor porte que fungiera como escudo protector.

\section{Puertas giratorias en la cárcel del corregimiento de Paucarcolla (1647-1649)}

Nuestro segundo caso de estudio se sitúa en la ribera opuesta del lago Titicaca, y tiene como protagonistas principales al corregidor de Paucarcolla, don Diego de Llanos, y a los caciques de los pueblos de Vilque, Puno, Icho, Coata, Capachica, Paucarcolla y Tiquillaca ${ }^{26}$. Entre septiembre de 1647 y abril de 1649, el corregidor emitió cuatro mandamientos requisitorios destinados a los caciques de cada pueblo intimándolos al pago de los tributos adeudados (correspondientes a los tercios de San Juan y Navidad de 1647 y 1648). Como respuesta a cada exhorto, los caciques se declararon insolventes, amparándose en el clásico argumento de la "disipación" de sus pueblos y su extrema pobreza. Los caciques de Puno alegaron que todos sus yndios estan ausentes $y$ huidos del pueblo en muchos valles remotos de miedo de la mita de Potosi, mientras que los de Coata aclararon que ellos son tan pobres que ni tienen tierras ni punas ni ganados ni otros generos por ser uros pobres de la laguna ${ }^{27}$. La poca suma de dinero que tenían pagada procedía de la venta de su propio alimento: en septiembre de 1648, fueron rematadas 24 cargas de chuñu embargadas de los caciques de Vilque a tres pesos cada una, lo que montó un total de apenas $72 \operatorname{pesos}^{28}$.
En cada oportunidad, asistimos al estilado protocolo administrativo: (1) auto del corregidor encargando a un alguacil el cobro del tercio adeudado; (2) declaración de insolvencia de los caciques; (3) embargo de sus bienes; (4) remate en pública almoneda; (5) apresamiento de los caciques; (6) solicitud de liberación; (7) auto de liberación para la cancelación de la deuda (López Beltrán 1998:212). Cada uno de estos segmentos del ciclo destaca diferentes aspectos de las relaciones políticas a escala del corregimiento. En primer lugar, la lectura cruzada de los cargos imputados a los caciques de cada pueblo y de los resultados de la visita ordinaria efectuada por el corregidor en 1647, reflejados en los padrones elaborados en 1649, permiten evaluar la variación de la exacción tributaria en comparación con las tasas toledanas. La tendencia general revela una reducción de la tasa en plata, con extremos en el caso de Coata $(11,3 \%$ ) y Paucarcolla $(45,9 \%)$, con un único caso de incremento (48,4\% para Vilque), mientras que las tasas en especie se mantuvieron con escasas modificaciones (reducción del 17,2\% de la tasa en chuñu en Capachica y eliminación de la entrega de hechuras en Paucarcolla, compensada por la duplicación del número de llamas). También verificamos la reducción de la población tributaria denunciada por los caciques, cuya caída osciló entre el 79,5\% (Coata) y el 95,5\% (Paucarcolla) respecto de las cifras de 1573.

Desconocemos en qué contextos se produjeron las variaciones de los montos y rubros de las tasas de cada pueblo, toda vez que no disponemos de información de retasas en el corregimiento de Paucarcolla; queda pendiente una evaluación de la situación de cada pueblo para explicar los pormenores de esas transformaciones. De cualquier modo, es claro que el pronunciado descenso de la población tributaria dificultaba el pago del tributo, sea cual fuera la composición de la tasa.

En segundo lugar, mediante este expediente accedemos a la estructura de ayllus de cada pueblo y al elenco de autoridades que enfrentó los embates del corregidor Llanos. Esta instantánea de la composición interna del corregimiento de Paurcarcolla resulta fundamental, porque nos permite identificar tanto las transformaciones en la estructura de ayllus (fisión, fusión, variaciones demográficas, territorialidad) como los derroteros de los mismos caciques en otra documentación (ver Tabla 1) ${ }^{29}$. Creemos que esto constituye un avance significativo a la hora de otorgar visibilidad 
Tabla 1. Estructura interna de los pueblos del corregimiento de Paucarcolla (1649)

\begin{tabular}{|c|c|c|c|c|c|}
\hline Pueblo & Autoridades & \multicolumn{2}{|c|}{ Ayllu } & Trib & $\%$ \\
\hline Vilque & $\begin{array}{l}\text { Don Pedro Layme (CG) } \\
\text { Don Gabriel Maqueda (2P) }\end{array}$ & \multicolumn{2}{|c|}{ Hilata / Utuata / Monaipa / Cazador } & 53 & 15,6 \\
\hline Puno & $\begin{array}{l}\text { Don Juan Gómez Coaquira (CG) } \\
\text { Don Pablo Layme (2P) }\end{array}$ & \multicolumn{2}{|c|}{ Paxsa / Sirvi / Varaia / Uctumu / Hilave / Chuca / Caruma } & 26 & 7,7 \\
\hline Icho & $\begin{array}{l}\text { Don Pedro Yaure / Ayavire / } \\
\text { Coavire (CPG) } \\
\text { Don Francisco Mamani (2P) }\end{array}$ & \multicolumn{2}{|c|}{$\begin{array}{l}\text { Collana / Pusi Chapi / Collana Siquiña / Sulca Siquiña / } \\
\text { Ayamora }\end{array}$} & 10 & 2,9 \\
\hline Coata & $\begin{array}{l}\text { Don Diego Coaricona }(\mathrm{CG}) \\
\text { Don Francisco Escapacoila / } \\
\text { Capacacoila }(\mathrm{CG})\end{array}$ & \multicolumn{2}{|c|}{ Collana / Carata } & 91 & 26,9 \\
\hline \multirow[t]{2}{*}{ Capachica } & $\begin{array}{l}\text { Don Juan Cajia / Caquia (CP) } \\
\text { Don Carlos Callasa / Callata (CG) }\end{array}$ & Urco & $\begin{array}{l}\text { Hilata / Queescapa / Araga / Sequecha / Capano } \\
\text { / Amantani / Escallani Uro / Uro Çollagache / } \\
\text { Silagache / Utuele Uro / Lachiuni Uro }\end{array}$ & 78 & 23 \\
\hline & & Uma & Sucata / Ynga / Taquile / Uro & & \\
\hline Paucarcolla & $\begin{array}{l}\text { Don Garcia Pari Aguela / } \\
\text { Pareguela / Paregoila (CG) } \\
\text { Don Juan Are / Ticona (2P) }\end{array}$ & \multicolumn{2}{|c|}{$\begin{array}{l}\text { Collana / Pacara / Chicalla / Socava / Collagua / Yanico / } \\
\text { Arina de uros / Pugserin / Cotos / Cupe }\end{array}$} & 45 & 13,3 \\
\hline \multirow[t]{2}{*}{ Tiquilllaca } & $\begin{array}{l}\text { Don Pedro Uruche (CG) } \\
\text { Don Juan Pizarro }(2 \mathrm{P})\end{array}$ & \multicolumn{2}{|c|}{ Collana } & 36 & 10,6 \\
\hline & & & Total tributarios & 339 & 100 \\
\hline
\end{tabular}

a estos actores políticos hasta ahora acallados por el silencio documental.

Cada uno a su turno, los caciques se declararon insolventes frente a los reclamos del corregidor y las presiones de su alguacil. Los autos de embargo revelan aspectos de la vida cotidiana de estos caciques, tales como sus condiciones de vivienda y su cultura material. El corregidor enumeró los bienes embargados a los caciques de Vilque: tres chuses de su dormir dos mantas y una montera y tres redes desparto de pescar y algunos pellejos y cantaros; por otra parte, en el guasi y casa del casique del pueblo de Puno halle dos chuses de su dormir y una camiseta vieja y mantas y muchos cantaros y ollas $^{30}$. Además de mantas para dormir y piezas de indumentaria viejas y de baja calidad y escaso valor monetario (sombreros, capas, calzones), el corregidor halló y embargó gran cantidad de cántaros y ollas para el almacenamiento, distribución y consumo de chicha, lo que informa de las prácticas de comensalidad, hospitalidad y ritualidad que estas autoridades desplegaban entre los colectivos que lideraban y en las que descansaba su legitimidad (Cummins 2002; Nielsen 2006).

Debido a que el remate de sus bienes poco dinero aportó, los caciques fueron llevados a la cárcel pública del pueblo de Guancané, residencia del corregidor. Pasados entre dos y cuatro días, los caciques hicieron notar a Llanos lo contraproducente de su prisión para el pago del tributo, el qual es ynposible enterar estando aqui porque antes se nos an de huir los pocos yndios que an quedado y a de aver cada dia mas resago a que no debe dar lugar Vuestra Merçed $^{31}$. El corregidor liberó a los caciques con el objetivo de que pudieran recolectar el tributo adeudado, para volver a apresarlos seis meses después una vez vencido el siguiente tercio. El ciclo se reinició, pues, cuatro veces sucesivas (septiembreoctubre de 1647, marzo-abril y septiembre-octubre de 1648 y marzo-abril de 1649). Tanto al momento de las requisas como al solicitar sus salidas de la cárcel, todos los caciques esgrimieron argumentos uniformes, lo que podría responder a acuerdos previamente entablados, a una práctica derivada de la experiencia acumulada o del asesoramiento del protector de naturales (figura llamativamente ausente entre los folios del expediente).

Finalizado su oficio como corregidor de Paucarcolla, en octubre de 1649 Llanos rindió cuentas ante su sucesor, quien registró en su favor la cobranza de 17.092 pesos ensayados por los cuatro tercios anteriores, cifra que apenas se acercaba al total de la tasa en plata correspondiente a un año $(17.225 \text { pesos ensayados })^{32}$. Ahora bien, apenas 
siete meses antes, en marzo de ese año, Llanos había encarcelado por cuarta vez consecutiva a todos los caciques del corregimiento por la deuda del tercio de Navidad de 1648. ¿De dónde provenía tal cantidad de dinero? Parece poco probable que los caciques hayan cancelado gran parte de sus deudas. ¿Provendría ese monto del propio peculio del corregidor, como salvaguarda ante el inminente juicio de residencia?

Nuevamente, los hilos del poder colonial se cortaron por lo más delgado. Don Pedro Layme, cacique de Vilque, preso de la rexa en la cárcel de Guancané, junto con el resto de sus pares del corregimiento, extenuaron al máximo tanto el potencial productivo de sus ayllus como los mecanismos administrativos para salir de prisión; a los pocos meses, volverían al mismo punto de partida, en un círculo vicioso del que difícilmente podían escapar.

\section{Consideraciones finales: evaluando el impacto de la prisión de los caciques}

La reconstrucción literaria que abre este trabajo resulta ilustrativa de las condiciones de vida de quienes pasaron sus días en la cárcel de La Paz. Engrillados, encadenados, encepados, encerrados y castigados corporalmente, los caciques presos en las cárceles públicas se vieron imposibilitados para articular los circuitos reciprocitarios, redistributivos y mercantiles o para auspiciar tareas productivas, mecanismos claves en el mantenimiento de su capital relacional, la reproducción de sus liderazgos y la eventual conformación de nuevas redes sociales (Morrone 2016:212). Su aislamiento recurrente ponía en suspenso (más o menos transitorio) las tramas relacionales que constituían las bases de su poder. El circuito de endeudamiento, embargo, remate, prisión y absolución, recreado una y otra vez, erosionaba la legitimidad de estas figuras ante sus propios sujetos y ante el resto de los segmentos de la sociedad colonial (Monsalve Zanatti 1998:391392; de la Puente Luna 2007:168-169).

¿Cuál fue el impacto de la prisión de los caciques entre la población nativa? En ausencia del referente que fungiera como "cabeza" del cuerpo político, los miembros de los ayllus bien podían reorientar sus lealtades hacia otras figuras de liderazgo en disponibilidad o bien desplegar estrategias de corte colectivo, como la migración y el reasentamiento en destinos más auspiciosos. En efecto, ambas opciones parecieron ser la causa y la consecuencia de la caída en desgracia de los caciques presos. Por un lado, la continuidad de las actividades productivas y el cumplimiento de las exigencias tributarias en ausencia del cacique principal bien pudo haber recaído en algún miembro de su parentela, en alguna autoridad menor del pueblo (segunda persona, principales, alcaldes) o en alguna figura ajena al elenco cacical pero con los medios suficientes como para encauzar la contingencia. A largo plazo, entendemos que la recurrente ausencia de los caciques principales contribuyó al desdibujamiento de la propia institución cacical y a la consecuente cristalización de liderazgos de base, proceso que se consolidaría a mediados del siglo XVIII (Thomson 2006). Por otro lado, la apelación a la "disipación" de los pueblos constituía una estrategia discursiva recurrente ante las instancias judiciales. Aquello que en el discurso cacical aparecía como "despoblamiento" o descenso de la población tributaria remitía, en términos de la dinámica sociodemográfica, a ciclos periódicos de desplazamiento y ocupación territorial en otros espacios (haciendas hispanocriollas, pueblos emplazados en los corregimientos libres de mita, ciudades) que morigeraban los efectos disruptivos de las cargas coloniales (Saignes 1984, 1985, 1987a). En efecto, el potencial reproductivo y la propia composición interna de los ayllus debieron verse severamente impactados por el debilitamiento y ausencia de sus autoridades máximas.

Una toma de distancia respecto de los alegatos cacicales acerca de su pobreza constituye un resguardo metodológico esencial, toda vez que el refuerzo de su condición de "pobres de solemnidad" cuadraba en los moldes que el sistema jurídico hispánico contemplaba para la población nativa y sus autoridades (López Beltrán 1998:212; Morrone 2015). Si bien existe la posibilidad de que algunos caciques hayan logrado diluir y ocultar sus riquezas materiales, el registro documental relevado en este trabajo arroja un panorama de despojo extremo, evidenciado en los rasgos de la cultura material que asoman entre los autos de embargo labrados contra los caciques de Paucarcolla; más aún si hacemos dialogar esos objetos con los declarados por los grandes caciques surandinos en sus piezas testamentarias o si comparamos la precariedad de sus viviendas ("guasis") con la opulencia y "aderezo" de la morada de don Gabriel Fernández Guarachi en Potosí. Los contrastes son por demás notorios, más allá de cualquier posible estrategia de ocultamiento. 
El cacique de Guaqui, por su parte, tuvo a mano otras herramientas. Al menos en dos oportunidades, don Baltasar Guamani se resguardó bajo la capa de dos grandes caciques del corregimiento de Pacajes. Ahora bien, el escudamiento detrás de figuras políticas de mayor porte presentaba sus bemoles: contribuía al acrecentamiento y consolidación del capital político de los grandes caciques, quienes "amasaban sus fondos de poder" (Sahlins 1979:275) a costa de cierta subordinación de los caciques de menor valía; la misma coyuntura generaba, pues, procesos simultáneos de desgranamiento y encumbramiento de sendos liderazgos políticos.

Estos procesos explican el ahondamiento de la brecha entre unos y otros. Entendemos que ese distanciamiento político propició el despliegue de relaciones de patronazgo tramadas entre ambos extremos. Como forma de subordinación interpersonal anclada en el lenguaje del parentesco (Campagno 2009) y pieza medular de la cultura jurídica y de la práctica política en la monarquía hispánica (Imízcoz Beunza 2016), el patronazgo constituyó un "lenguaje compartido" entre los segmentos nativos e hispanocriollos de la sociedad colonial. En este sentido, consideramos fructífero un camino analítico que atienda a los mecanismos de formación, integración y reproducción de las redes de poder local, tramadas tanto entre los caciques de distintos pueblos de reducción como entre estos y otras autoridades como los corregidores o los curas doctrineros.

Otra vía para evaluar los impactos reseñados, tanto entre la población tributaria como entre los propios caciques, podría orientarse hacia lecturas comparadas respecto de la situación de varios pueblos. En el corregimiento de Paucarcolla, los pueblos de Coata y Capachica presentaban, para 1649 , la mayor cantidad de tributarios ( 27 y $26 \%$ del total), aunque Coata había sufrido una menor merma respecto de la visita toledana $(79,5 \%)$ frente a otros como Guaqui (84\% para 1645) o Capachica $(94 \%)$. Por otro lado, apreciamos una marcada oposición entre las situaciones de Vilque (aumento de tasa en plata en $47 \%$, con una reducción del $83,5 \%$ de la población tributaria) y Paucarcolla (reducción de tasa en plata del 45,9\% con una caída del $95,5 \%$ de la masa tributaria) respecto de los tiempos toledanos. $\mathrm{La}$ comparación también opera como hermenéutica desde una perspectiva diacrónica. En tiempos toledanos, los caciques de Capachica poseían una gran riqueza ganadera que derivaba en una especialización textil sostenida (Bouysse-Cassagne 2010). Reconstruir los factores que, siete décadas después, llevaron tantas veces a sus sucesores a la cárcel pública de Guancané constituye una (micro)historia aún por escribir (Thomson 2006:79-85).

Finalmente, una lectura general de los casos aquí presentados revela un tratamiento diferencial dado por las autoridades coloniales a los caciques presos por deudas de tributo y a aquellos presos por temas tocantes a la mita potosina. ¿Por qué los caciques presos en la cárcel pública de Potosî recibían castigos corporales y peor tratamiento que sus pares presos en La Paz o en los pueblos de reducción, donde apenas pasaban unos días antes de ser soltados, para retornar a los pocos meses? ¿A qué factores obedecía este protocolo diferenciado? ¿Se tramaban en La Paz y Potosí tensiones políticas diferenciadas? ¿Acaso el incumplimiento de las obligaciones mitayas constituía una falta más grave que el rezago en el pago de los tributos? ¿Fueron las autoridades potosinas particularmente más propensas al castigo físico que los corregidores del lago, más preocupados por sus negocios personales que en el saneamiento del real erario? ¿Acaso en Potosí, polo dinamizador de la economía surandina, los caciques habían agotado su arsenal estratégico y se encontraban más expuestos al rigor de las autoridades hispanas? La concentración de casi el 85\% de los casos relevados (27 sobre 32 ) en el período 1600-1637 coincide con el despegue de la crisis de la minería potosina, lo que muy probablemente haya acortado los márgenes de acción de los caciques y reforzado el carácter coactivo de las autoridades a cargo de la administración de la mano de obra (Zagalsky 2014b). En este contexto, es lógico colegir que los negocios e intereses atados al rendimiento de la producción minera demandaran controles más estrictos que aquellos que los corregidores, en apenas dos años de oficio, pudieran garantizar con el cobro de los tributos. Futuros trabajos de análisis comparativo de las coyunturas políticas locales en Potosí, La Paz y cada corregimiento del lago podrán echar luz acerca de estos interrogantes, esbozados aquí a modo de agenda de investigación.

Entendemos que estos (y tantos otros) interrogantes evidencian hasta qué punto los liderazgos étnicos del mundo andino colonial continúan representando un campo fértil de investigación histórica, enriquecido por nuevas lecturas de nuevas (o de las ya revisadas) piezas documentales. A medio siglo de la publicación en francés de La visión de 
los vencidos de Nathan Wachtel, obra pionera en el estudio de las transformaciones acaecidas entre los caciques andinos, este aporte referente a los caciques menos afamados del lago Titicaca contribuye, según entendemos, a delinear con mayor claridad los trazos más débiles de la matriz colonial del poder en el espacio lacustre.

\section{Agradecimientos}

Este trabajo fue realizado en el marco de los Proyectos PICT 2016-0481 y UBACyT F291, dirigidos por Ana María Presta, y FiloCyT 19-039, dirigido por el autor. Agradecemos los aportes críticos de los evaluadores de Diálogo Andino.

\section{Referencias Citadas}

Abercrombie, T. A.

1998 "Tributes to bad conscience: charity, restitution, and inheritance in cacique and encomendero testaments of sixteenth-century Charcas". En Dead Gieveaways. Indigenous Testaments of Colonial Mesoamerica and the Andes, Susan Kellogg y Matthew Restall eds., 249-289. Salt Lake City: The University of Utah Press.

Agüero, A.

2005 "Ciudad y poder político en el Antiguo Régimen. La tradición castellana". Cuadernos de Historia 15: 237-310.

Argouse, A.

2015 "Archivos de la vulnerabilidad. Reos en Santiago de Chile (1650-1780)". Clio \& Crimen 12: 191-214.

Belan, C.

2018 "Crimen y castigo: prisiones y confinamiento a finales de la colonia. La real cárcel de Arequipa, 1780-1824". Memoria y Civilización 21: 525-547.

Bouysse-Cassagne, $\mathrm{T}$.

2010 "Apuntes para la historia de los puquinahablantes". Boletín de Arqueología PCUP 14: 283-307.

Bromley, J.

2005 Las Viejas Calles de Lima. Lima: GECyD-Municipalidad Metropolitana de Lima.

Burns, K.

2011 "Making indigenous archives: the quilcaycamayoc of colonial Cuzco". Hispanic American Historical Review 91 (4): 665-689.

Campagno, $\mathrm{M}$.

2009 "Tres modos de existencia política: jefatura, patronazgo y Estado". En Parentesco, Patronazgo y Estado en las Sociedades Antiguas, M. Campagno ed., 341-351. Buenos Aires: FFyL-UBA.

Castro Flores, N.

2019 "Estrategias familiares, práctica jurídica y comunidad de memoria. Los descendientes de Tito Alonso Atauchi y Viracocha Inca en Charcas, Siglos XVI-XVIII". Estudios Atacameños 61: 177-198.

Charles, J.

2010 Allies at Odds. The Andean Church and Its Indigenous Agents, 1583-1671. Albuquerque: University of New Mexico Press.

Choque Canqui, R.

1993 Sociedad y Economía Colonial en el Sur Andino. La Paz: Hisbol.

Choque Canqui, R.

2003 Jesús de Machaqa: la marka rebelde. Cinco siglos de historia. La Paz: Plural-CIPCA.
Choque Canqui, R.

2012 Mita, caciques y mitayos. Gabriel Fernández Guarache. Memoriales en defensa de los indios y debate sobre la mita de Potosí (1646-1663). Sucre: ABNB.

Cook, N. D.

1975 Tasa de la Visita General de Francisco de Toledo. Lima: UNMSM.

Copete, M.-L.

1990 "Criminalidad y espacio carcelario en una cárcel del Antiguo Régimen. La cárcel real de Sevilla a finales del siglo XVI”. Historia Social 6: 105-125.

Cummins, $\mathrm{T}$.

2002 Toasts with the Inca. Andean Abstraction and Colonial Images on Quero Vessels. Ann Arbor: The University of Michigan Press.

De la Puente Luna, J. C.

2007 Los Curacas Hechiceros de Jauja. Batallas Mágicas y Legales en el Perú Colonial. Lima: PCUP.

De la Puente Luna, J. C.

2014 "The many tongues of the King: indigenous language interpreters and the making of the Spanish Empire". Colonial Latin American Review 23 (2): 143-170.

De la Puente Luna, J. C.

2015 "That which belongs to all: khipus, community, and indigenous legal activism in the early colonial Andes". The Americas 72 (1): 19-54.

De la Puente Luna, J. C.

2018 Andean Cosmopolitans. Seeking Justice and Reward at the Spanish Royal Court. Austin: University of Texas Press.

Del Río, M. M.

2005 Etnicidad, Territorialidad y Colonialismo en los Andes: Tradición y cambio entre los soras de los siglos XVI y XVII. La Paz-Lima: IEB-IFEA.

Del Río, M.

2018 "Dinastías señoriales y transformaciones territoriales en los sura de Tapacarí. S. XVI-XVII”. En Interpretando Huellas: Arqueología, Etnohistoria y Etnografía de los Andes y sus Tierras Bajas, María de los Ángeles Muñoz ed., 391-408. Cochabamba: Kipus.

Diez Hurtado, A.

2006 "Los problemas del poder: política local y gobierno en las reducciones de la costa de Piura, siglo XVII". Anthropologica 24: 107-127.

Dueñas, A.

2010 Indians and Mestizos in the "Lettered City". Reshaping Justice, Social Hierarchy, and Political Culture in Colonial Peru. Boulder: University Press of Colorado. 
Espinoza Soriano, W.

1981 "El reino aymara de Quillaca-Asanaque, siglos XVXVI". Revista del Museo Nacional XLV: 175-274.

Feyles, G.

1965 Actas Capitulares de la Ciudad de La Paz 1548-1562.

La Paz: Municipalidad de La Paz.

Foucault, M.

1996 La Vida de los Hombres Infames. La Plata: Caronte.

Glave, L. M.

1989 Trajinantes. Caminos Indígenas en la Sociedad Colonial. Siglos XVI / XVII. Lima: IAA.

Glave, L. M.

2006 "Gestiones transatlánticas. Los indios ante la trama del poder virreinal y las composiciones de tierras (1646)". Revista Complutense de Historia de América 34: 85-106.

Graubart, K. B.

2016 "Competing Spanish and indigenous jurisdictions in early colonial Lima". En Oxford Research Encyclopedia in Latin American and Caribbean History, Kenneth Mills ed., 1-29. New York: Oxford University Press.

González Casanovas, I.

2000 Las Dudas de la Corona. La Política de Repartimientos para la Minería de Potosí (1680-1732). Madrid: CSIC.

Harris, O., B. Larson y E. Tandeter comps.

1987 La Participación Indígena en los Mercados Surandinos. Estrategias y Reproducción Social, Siglos XVI-XX. La Paz: CERES.

Hespanha, A. M.

1993 La Gracia del Derecho. Economía de la Cultura en la Edad Moderna. Madrid: CEC.

Imízcoz Beunza, J. M.

2016 "Las relaciones de patronazgo y clientelismo. Declinaciones de la desigualdad social". En Patronazgo y Clientelismo en la Monarquía Hispánica (Siglos XVIXIX), José María Imízcoz Beunza y Andoni Artola Renedo coords., 19-41. Bilbao: Universidad del País Vasco.

Jurado, M. C.

2004 "Las reducciones toledanas a pueblos de indios: aproximación a un conflicto. El repartimiento de Macha (Charcas), siglo XVI". Cahiers des Amériques Latines 43 (3): 123-137.

Jurado, M. C.

2014 "Descendientes de los primeros. Las probanzas de méritos y servicios y la genealogía cacical. Audiencia de Charcas, 1574-1719”. Revista de Indias 71: 387-422.

Lohmann Villena, G.

2001 [1957] El Corregidor de Indios en el Perú bajo los Austrias. Lima: PCUP.

López Beltrán, C.

1998 Alianzas Familiares. Elite, Género y Negocios en La Paz, s. XVII. Lima: IEP.

Matienzo, J. de.

1967 [1567] Gobierno del Perú. Paris-Lima: IFEA. Ed. Guillermo Lohmann Villena.

Medinacelli, X.

2010 Sariri. Los llameros y la construcción de la sociedad colonial. Lima-La Paz: IFEA-Plural.

Medinacelli, X. y M. Inch (coords.).

2010 Pleitos y Riqueza. Los Caciques Andinos en Potosí del Siglo XVII. Sucre: ABNB.
Monsalve Zanatti, M.

1998 "Miserables e idólatras: Los curacas frente a la administración eclesiástica". Actas del IV Congreso Internacional de Etnohistoria 3: 376- 398, Lima: PCUP.

Moreno, S. y F. Salomon (comps.).

1991 Reproducción y Transformación de las Comunidades Andinas, Siglos XVI-XX. Quito: Abya Yala.

Morong Reyes, G.

2016 Saberes Hegemónicos y Dominio Colonial. Los Indios en el Gobierno del Perú de Juan de Matienzo (1567). Rosario: Prohistoria.

Morrone, A. J.

2011 "Territorialidad y liderazgo étnico entre la reducción y la revisita: los caciques de San Pedro y Santiago de Chuquiabo (1573-1630)". Revista Andina 51: 163-194.

Morrone, A. J.

2013 "Estrategias estatales y liderazgo étnico en el corregimiento de Pacajes (1538-1620)". En Presta, Aportes Multidisciplinarios, 343-372.

Morrone, A. J.

2015 "Memoria en la sangre y en la tierra. Liderazgo, sucesión y territorialidad en el sur andino (corregimiento de Pacajes, 1570-1650)". Indiana 32: 205-234.

Morrone, A. J.

2016 "No todos los caciques fueron mallku. Mediación política truncada en los corregimientos de Pacajes y Omasuyos (Audiencia de Charcas, 1570-1630)". Diálogo Andino 50: 207-217.

Morrone, A. J.

2019 "Entre altares y escritorios. Liderazgo étnico y poder local en la pluma de tres curas-cronistas del Lago Titicaca (1570-1650)". Memoria Americana 27 (1): 51-86.

Mumford, J. R.

2012 Vertical Empire. The General Resettlement of Indians in the Colonial Andes. Durham-Londres: Duke University Press.

Murra, J. V.

1977 "La correspondencia entre un "capitán de la mita" y su apoderado en Potosî". Historia y Cultura 3: 45-58.

Nielsen, A. E.

2006 "Plazas para los antepasados: Descentralización y poder corporativo en las formaciones políticas preincaicas de los Andes circumpuneños". Estudios Atacameños 31: 63-89.

Oliveto, L. G.

2017 "Don Diego de Espeloca, curaca de los chichas: vinculaciones interétnicas y construcción de liderazgo en la frontera de Tarija, siglo XVI". Boletín del Instituto de Historia Argentina y Americana "Dr. Emilio Ravignani" 46: 15-44.

Pease G. Y., F.

1992 Curacas, Reciprocidad y Riqueza. Lima: PCUP.

Platt, T.

1978 "Mapas coloniales de la provincia de Chayanta: dos visiones conflictivas de un solo paisaje". Estudios Bolivianos en Homenaje a Gunnar Mendoza L. La Paz: UMSA, 101-118.

Platt, T., T. Bouysse-Cassagne y O. Harris.

2006 Qaraqara-Charka. Mallku, Inka y Rey en la Provincia de Charcas (siglos XV-XVII). Historia antropológica de una confederación aymara. La Paz: IFEA-Plural. 
Presta, A. M. (ed.).

2013 Aportes Multidisciplinarios al Estudio de los Colectivos Étnicos Surandinos. Reflexiones sobre Qaraqara-Charka Tres Años Después. La Paz: IFEA-Plural.

Quispe-Agnoli, R.

2016 Nobles de Papel. Identidades Oscilantes y Genealogías Borrosas en los Descendientes de la Realeza Inca. Madrid: Iberoamericana Vervuert.

Ramos, G.

2016 "El rastro de la discriminación. Litigios y probanzas de caciques en el Perú colonial temprano". Fronteras de la Historia 22 (1): 66-90.

Rebagliati, L. E.

2018 "La cárcel del cabildo de Buenos Aires y sus fuentes: aproximaciones, problemas y potencialidades (1776-1821)". Revista de Historia de las Prisiones 6: 97-123.

Rivera Cusicanqui, S.

1978 "El mallku y la sociedad colonial en el siglo XVII: el caso de Jesús de Machaca". Avances 1: 7-27.

Rostworowski, M.

1985-1986 "La tasa toledana de Capachica de 1575". Histórica 35: 43-79.

Sahlins, M. D.

1979 "Hombre pobre, hombre rico, gran hombre, jefe: tipos políticos de Melanesia y Polinesia”. En Antropología Política, Josep R. Llobera comp., 267-288. Barcelona: Anagrama.

Saignes, $\mathrm{T}$

1984 "Las etnias de Charcas frente al sistema colonial (siglo XVII). Ausentismo y fugas en el debate sobre la mano de obra indígena, 1595-1665". Jahrbuch für Geschichte Lateinamerikas 21: 27-75.

Saignes, $\mathrm{T}$.

1985 Caciques, Tribute and Migration in the Southern Andes. Indian Society and the 17th Century Colonial Order (Audiencia de Charcas), Occasional Papers 14 Londres: ILAS-University of London.

Saignes, $\mathrm{T}$

1987a "Ayllus, mercado y coacción colonial: el reto de las migraciones internas en Charcas (siglo XVII)". En Harris et al., La Participación Indígena, 111-158.

Saignes, $\mathrm{T}$.

1987b "De la borrachera al retrato: los caciques andinos entre dos legitimidades (Charcas)". Revista Andina 9: 139-170.

Sarabia Viejo, M.J.

1989 Disposiciones Gubernativas para el Virreinato del Perú. 1569-1574. Sevilla: EEHA.

Spalding, K.

1974 De Indio a Campesino. Cambios en la Estructura Social del Perú Colonial. Lima: IEP.

Spedding, A.

1997 Manuel y Fortunato. Una Picaresca Andina. La Paz: Aruwiyiri.

Spurling, G.

1992 The organization of craft production in the Inka state: the potters and weavers of Milliraya. Ph.D. Dissertarion. Cornell University. Ann Arbor, MI: University Microfilm.

Stern, S. J.

1986 [1982] Los Pueblos Indígenas del Perú y el Desafío de la Conquista Española. Huamanga hasta 1640. Madrid: Alianza.
Stern, S. J.

1987 "La variedad y ambigüedad de la intervención indígena andina en los mercados coloniales europeos: apuntes metodológicos". En Harris et al., La Participación Indígena: 281-312

Torres de Mendoza, L.

1866 Colección de Documentos Inéditos Relativos al Descubrimiento, Conquista y Colonización de las Posesiones Españolas en América y Oceanía. Madrid: Imprenta de Frías y Cía. Tomo VI.

Thomson, S.

2006 Cuando Solo Reinasen los Indios. La Política Aymara en la Era de la Insurgencia. La Paz: Muela del Diablo-Aruwiyiri.

Villalba Pérez, E.

1993 "Algunas notas acerca de la gestión de las cárceles madrileñas a comienzos del siglo XVII". Boletín de la Facultad de Derecho 3: 311-327.

Wachtel, N

1976 [1971] Los Vencidos. Los Indios del Perú frente a la Conquista Española (1530-1570). Madrid: Alianza.

Wachtel, N

2001 El Regreso de los Antepasados. Los Indios Uros de Bolivia, del Siglo XX al XVI. México: El Colegio de México, Fideicomiso de las América, Fondo de Cultura Económica.

Wernke, S. A.

2007 ENegotiating community and landscape in the Peruvian Andes: a transconquest view". American Anthropologist 109 (1): 130-152.

Yannakakis, Y.

2013 "Indigenous people and legal culture in Spanish America". History Compass 11 (11): 931-947.

Zagalsky, P. C.

2013 "Tensiones, disputas y negociaciones en torno a la posesión de la tierra. Un mapeo histórico del espacio de los visisa. Andes meridionales, 1570-1610”. En Presta, Aportes Multidisciplinarios, 191-227.

Zagalsky, P. C.

2014a "La mita de Potosí: una imposición colonial invariable en un contexto de múltiples transformaciones (siglos XVIXVIII: Charcas, Virreinato del Perú)". Chungara. Revista de Antropología Chilena 46 (3): 375-395.

Zagalsky, P. C.

2014b "Trabajadores indígenas mineros en el Cerro Rico de Potosí: tras los rastros de sus prácticas laborales (siglos XVI y XVII)". Mundos do Trabalho 6 (12): 55-82.

Ziemendorff, $\mathrm{S}$.

2016 "Revisión de argumentos respecto al hipotético asesinato del Inca Huayna Capac". Uku Pacha. Revista de Investigaciones en Ciencias Sociales y Humanidades 20: $5-25$.

Zuloaga Rada, M.

2012 La Conquista Negociada: Guarangas, Autoridades Locales e Imperio en Huaylas, Perú (1532-1610). Lima: IEP-IFEA.

\section{Archivos}

Archivo del Arzobispado de La Paz, Cabildo de la Catedral, Tomo 1.

Archivo y Biblioteca Nacionales de Bolivia (ABNB, Sucre). 
Expedientes Coloniales (EC) 1649-20.

Minas (Min) 122-3 / 123-11.

Archivo General de Indias (AGI, Sevilla).

Audiencia de Charcas 52.

Escribanía de Cámara 868A, primera pieza.

Archivo General de la Nación (AGN, Buenos Aires).

Sala IX, Legajo 17-1-4.

Sala IX, Legajo 20-4-4.

Sala XIII, Legajo 17-2-3.

Archivo Histórico de Jujuy, Archivo del Marquesado de Tojo, Carpeta 271.

Archivo Histórico de Potosí, Escrituras Notariales 44: Pedro de Venegas.
Archivo de La Paz (ALP, La Paz)

Cajas Reales (CR) 1600 Caja 2 Documento 4 / 1616-1624 C2 D6 / 1631 C4 D4.

Expedientes Coloniales (EC), Caja 3 Expediente 13 / C5 E25 / C6 E23 / C8 E9 / C11 E3 / C15 E32 / C22 E32 / C25 E3.

Registro de Escrituras (RE). C9 L13, ff. 267r-268r: Andrés González de Vargas / C9 L13, ff. 419r-421v: Agustín de Atencia / C18 L29, ff. 243r-245v: Pedro de Manzaneda / C20 L33, ff. 454r-454v: Pedro de Manzaneda / C21 L34, ff. 360r-361v: Juan López Mexia / C21 L35, ff. 719v-720v: Pedro de Manzaneda / C23 L37, ff. 447r-447v, 505r-505v y 732r-734v: Juan López Mexia / C38 L56, s/f: Pedro de Manzaneda.

\section{Notas}

1 Entre los más renombrados y ricos caciques de los siglos XVI y XVII, encontramos a don Juan Colque Guarache, cacique de Quillacas y Asanaques (corregimiento de Paria, 1560-1584); don Diego de Espeloca, cacique de Talina (Chichas, 1573-1598); don Diego Chambilla, cacique de Pomata (Chucuito, 1616-1629); don Gabriel Fernández Guarachi, cacique de Jesús de Machaca (Pacajes, 16201673); don Fernando Ayra de Ariutu, cacique de Pocoata (Chayanta, 1630-1656?); don Bartolomé Tupa Hallicalla, cacique de Asillo (Azángaro, 1648-1675); y don Pedro Chipana, cacique de Calamarca (Sicasica, 1675-1693). Cf. Murra 1977; Platt 1978; Espinoza Soriano 1981; Glave 1989:279-304; Pease 1992:158-162; Choque Canqui 1993, 2003, 2012; Abercrombie 1998; Medinacelli e Inch 2010; Oliveto 2017.

2 Así como ocurría en otras ciudades coloniales como Santiago de Chile, Buenos Aires o Arequipa (Argouse 2015; Rebagliati 2018; Belan 2018) o en Madrid y Sevilla para la misma época (Copete 1990; Villalba Pérez 1993).

3 Archivo de La Paz (ALP), Registro de Escrituras (RE), Caja 38, Legajo 56, s/f: Pedro de Manzaneda (1660). Se trata de la actual calle Comercio al 1200, entre Bolívar y Colón, que López Beltrán (1998:33) denomina como calle "de la cárcel". En septiembre de 1625, don Juan de Pisa Saavedra, notable vecino paceño, protocolizó una escritura de donación en favor de Constanza Ortiz de Vargas por un pedaso de solar que tengo e poseo tras el corral de la carcel biexa (...) de las [casas] de Luis de Losa que solia ser carçel publica. ALP RE C18 L29, ff. 243r-245v: Pedro de Manzaneda.

4 Apenas logramos identificar a cuatro alcaides: Francisco Trujillo en 1609 (ALP RE C9 L13, ff. 419r-421v: Agustín de Atencia); Antonio González en 1630-1631 (ALP RE C21 L34, ff. 360r-361v: Juan López Mexia; ALP Expedientes Coloniales (EC) C8 E9); Alonso de Mena en 1636 (Archivo del Arzobispado de La Paz, Cabildo de la Catedral, Tomo 1, ff. 172r-172v) y Alonso Rodríguez de Porres en 1668-1676 (ALP EC C22 E32; ALP EC C25 E3, f. 6r-7v). También sabemos que el sábado 23 de octubre de 1632 se efectuó una visita reglamentaria. ALP RE C23 L37, ff. 505r-505v: Juan López Mexia.

5 Matienzo 1967:49-50 [1567]. Cf. asimismo Jurado 2004 y Morong Reyes 2016:196-198.
$6 \quad$ Instrucción y ordenanzas de los corregidores de naturales. Los Reyes, 30 de mayo de 1580. Ordenanza 8 (Saravia Viejo 1989;II:415; Lohmann Villena 2001:285 [1957]).

7 Archivo y Biblioteca Nacionales de Bolivia (ABNB, Sucre), Minas (Min) 122-3, ff. 16v-17r.

8 Archivo General de Indias (AGI, Sevilla), Audiencia de Charcas 52, f. 798v.

9 Archivo General de la Nación (AGN, Buenos Aires), Sala XIII, Legajo 17-2-3, f. 172r. Se trataba de don Juan Llacsa Guanca, cacique principal de la parcialidad hanansaya, y don Gonzalo Patillusco, su segunda persona; y de don Juan Bautista Villca Laura, cacique de hurinsaya, y don Francisco Vázquez su segunda persona.

10 AGI Escribanía de Cámara 868A, primera pieza, ff. 54v$55 \mathrm{r}$ y $214 \mathrm{r}-216 \mathrm{v}$.

11 ALP EC C3 E13 (1601), C5 E25 (1617), C8 E9 (1631), C11 E3 (1635), C15 E32 (1642); ALP RE C23 L37, ff. 447r-447v y 732r-734v: Juan López Mexia (1632-1633).

12 ALP EC C6 E23 (1619); ALP Cajas Reales (CR) 1631 Caja 4 Documento 4 (1626).

13 ABNB Min 122-3, f. 17v (1593); Archivo Histórico de Potosí, Escrituras Notariales 44, f. 84r: Pedro de Venegas (1612); ALP RE C20 L33, ff. 454r-454v: Pedro de Manzaneda (1630).

14 ALP CR 1600 C2 D4, ff. 32r-32v.

15 ALP CR 1616-1624, C2 D6, ff. 173r-173v.

16 ALP RE C21 L35, ff. 719v-720v: Pedro de Manzaneda. En 1623, don Sebastián Laura había ocupado el lugar de don Baltasar Guamani en la cárcel pública de La Paz.

17 ABNB Min 123-11, f. 15r.

18 Para 1573, cf. Cook 1975:53-54; para 1645, cf. AGN IX, 20-4-4.

19 AGI Escribanía 868A, primera pieza, ff. 77r-78r. Cf. Wachtel 2001:435-437.

20 ALP RE C9 L13, ff. 267r-268r: Andrés González de Vargas. 21 AGI Escribanía 868A, primera pieza, f. 178r. Como ya mencionamos, en 1647 el cacique de Jesús de Machaca debió pagar casi 4000 pesos a cinco azogueros potosinos para cubrir los mitayos faltantes de Guaqui.

22 Archivo Histórico de Jujuy, Archivo del Marquesado de Tojo, Carpeta 271, f. 3r.

23 AGI Escribanía 868A, primera pieza, f. 311v. En 1657, el corregidor había señalado específicamente que "se ahogaron 
mas de 400 yndios fuera de las mugeres e hijos" del pueblo de Guaqui (f. 77v).

24 AGI Escribanía 868A, primera pieza, f. 195r. Don Sebastián Marca había sido cacique de Julloma (f. 45r), mientras que don Juan Cupi Ticona lo fue de Tiwanaku hanansaya (AGI Charcas 52, f. 800r)

25 AGI Escribanía 868A, primera pieza, f. 284r. Ziemendorff (2016:12) sugiere que las referencias documentales a las muertes por envenenamiento, "de pesar" o "de pesadumbre" podían constituir eufemismos para el suicidio, práctica condenada por la Iglesia católica.

26 ABNB EC 1649-20. El expediente, que resume los cargos imputados al corregidor al finalizar su oficio, fue presentado ante su sucesor, el capitán don Juan de Cevericha y Herrera. Llanos había sido corregidor de Chumbivilcas en 1640 (Bromley 2005:225).

27 ABNB EC 1649-20, f. 23v. Cf. Saignes 1985:8. La debilidad de los caciques del corregimiento de Paucarcolla para garantizar el pago de los tributos se correspondía con las dificultades que manifestaban otros corregimientos del norte del lago (como Azángaro y Asillo o Canas y
Canchis, por ejemplo) para el entero de la mita potosina, condiciones que se mantendrían hasta fines del siglo XVII (Saignes 1987a; Glave 1989:231-277; González Casanovas 2000:165-188).

28 ABNB EC 1649-20, f. 5v.

29 De los caciques del corregimiento de Paucarcolla, cf. Rostworowski 1985-1986; Spurling 1992; BouysseCassagne 2010 y Morrone 2019. En la visita ordinaria de 1649 no figuran los ayllu Cocha de Vilque; Chimo Uros y Callancache y Guaje de Puno; Pacacache, Humogate, Pocosin y Lloco de Coata; y Jijone y Caminaca Uros de Paucarcolla, registrados en la visita general ordenada por el virrey Mancera en 1645 (AGN IX, 17-1-4), posiblemente porque el corregidor Llanos no hallara tributarios en ellos.

30 ABNB EC 1649-20, ff. 2v y $13 \mathrm{v}$.

31 ABNB EC 1649-20, ff. 2v-3r.

32 Estas cifras desmienten los alegatos del corregidor Llanos, quien se ufanaba de haber recaudado más dinero que su antecesor, don Bernardino de Salazar Carrillo, en menos tiempo. ABNB EC 1649-20, ff. 76v-77r. 